\title{
Answer to medical quiz: images
}

Answer 1. Erythema nodosum.

Answer 2. Bilateral hilar and right para-tracheal lymphadenopathy.

Answer 3. Tuberculin skin sensitivity test was performed and there is marked induration.

Answer 4. Primary tuberculosis.

\section{REVIEW}

Tuberculosis is an ancient disease and remains as a major public health problem through-out the world. ${ }^{1}$ One-third of the global human population is infected by Mycobacterium tuberculosis, the causative agent for tuberculosis. Most tuberculosis infections occur in childhood and remain asymptomatic or mild flu-like illness may occur. ${ }^{2}$ Pulmonary tuberculosis is the most common form; a primary sub-pleural infective focus (Gohn focus) along with draining lymphatic and regional (hilar) lymphadenopathy constitute Gohn complex, which may heal and calcify. Tubercular lymphadenopathy is common, may be primary or secondary. Erythema nodosum may be a presentation of primary tuberculosis ${ }^{3-5}$ and tuberculosis of any form. ${ }^{6,7}$ Patients with sarcoidosis may present with erythema nodosum and bilateral hilar lymphadenopathy but positive tuberculin test $(23 \mathrm{~mm}$ induration after 72 hours, ref $>10 \mathrm{~mm}$ ) excluded sarcoidosis in the index case. Most reported cases of erythema nodosum due to tuberculosis were treated with anti-tuberculosis drugs $\mathrm{s}^{3-7}$ but the case presented here did not receive any medication. Over watchful 4-years of follow-up, she remained in good health. This observation raises a research interest; as most primary tuberculosis cases are asymptomatic, should all erythema nodosum due to tuberculosis merit anti-tuberculosis drug treatment?

Conflict of interest: Nothing to declare.

Author's contribution: MAR evaluated and diagnosed the case, did follow-up, literature search and manuscript preparation.

\section{REFERENCES}

1. Rahim MA, Hossain M, Zaman S, Uddin KN. Recurrent urinary tract infection as presenting feature of genito-urinary tuberculosis: reports of two cases. BIRDEM Med J 2020; 10(3): 212-4.

2. Thomas TA. Tuberculosis in children. Pediatr Clin North Am 2017 August; 64(4): 893-909.

3. Kritsotakis E. Erythema nodosum as sign of primary tuberculosis. Oxford Medical Case Reports 2017; 8:147-9.

4. Kapse A. Erythema nodosum: presenting feature of primary pulmonary tuberculosis. Pediatric Infectious Disease 2012 April-June; 4(2): 91-3.

5. Acharya S. A case of tuberculous lymphadenitis with erythema nodosum. Ann Nigerian Medicine Jul-Dec 2011; 5(2): 65-7.

6. Koufakis T, Gabranis I. Erythema nodosum leads to the diagnosis of pulmonary tuberculosis. Pan African Medical Journal 2014; 18:291

7. Chowdhury AW, Alam MR, Saha A, Jamil MM. Renal tuberculosis in a middle aged woman presenting with asymptomatic microscopic haematuria and erythema nodosum. J Medicine 2009; 10: 132-4. 